\title{
A REVIEW OF RESEARCH ON THE ENGLISH TRANSLATION OF “CHU CI" IN THE PAST TWO DECADES
}

\author{
Pan Zhenxiao \\ Graduate Student, School of Foreign Studies, \\ Yangtze University, Hubei Province,
}

China

\begin{abstract}
:
This article reviews the English translation research of "Chu $\mathrm{Ci}^{\prime}$ in the past two decades. Based on statistics from CNKI, it is found that research on the English translation of "Chu $\mathrm{Ci}^{\prime}$ are presently confined to several translators' translations such as Waley, Hawkes and $\mathrm{Xu}$ Yuanchong, among which the interpretation of cultural images weighs heavily. Although interdisciplinary research has been realized rather than limited in the study of cultural images, there is no focused point only separated studies, which means the lack of comprehensive and systematic research on the English translation of "Chu Ci".
\end{abstract}

Keywords: Chu Ci; translator's translations; different perspectives; cultural images

\section{Introduction}

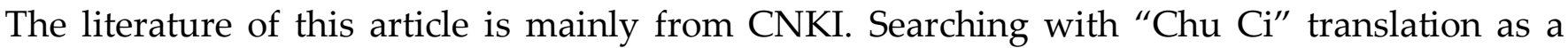
keyword, it is found that the translation research of "Chu $\mathrm{Ci}^{\prime}$ can be roughly divided into these categories: research on individual translator's translations; studies from different theoretical perspectives; studies on cultural images in "Chu $\mathrm{Ci}^{\prime}$; comparative analysis of Chinese and English translations. In Jingchu culture, "Chu Ci" is the research object of many scholars, and it is also the current research priorities. By combing the literature, we can understand the current situation and spread of the current study of "Chu Ci", and provide a reference for further study of Jingchu culture.

\section{Different translations}

The representative English translations of "Chu $\mathrm{Ci}$ " include selected editions by Herbert Allen Giles, selected editions by Arthur Waley, the full editions by the sinologist David Hawkes, selected editions of Burton Watson at aboard; selected editions of Lin Wenqing (1935), selected editions of Yang Xianyi (1953), selected editions of Sun Dayu (1966), selected editions of Xu

iCorrespondence: email 954220623@qq.com 
Yuanchong (1994) in China. Therefore, their translations of "Chu Ci" is always the focus of scholars.

Herbert Alen Giles, a well-known sinologist at the University of Cambridge in the United Kingdom, was one of the earliest Western scholars to translate the English version of "Chu Ci". Giles was not confined to his tradition of translating poetry, but he chose to keep the form and translate the "Chu Ci" in loose form. Giles' loose translation was free from rhyme, and his writing was more flexible and sincere (Yan Xiaojiang, 2017). After Giles, Waley's translation of "Chu Ci. Nine Songs" are published, which is based on the theme of witch culture. It was not until the publication of Willy's "Nine Songs" that the study of the theme of "Chu Ci" works appeared in the British Sinology. Some scholar (Zhang Xiao, 2010) compared Waley's understanding of "Chu $\mathrm{Ci}$ - Nine Songs" with the works of Chinese scholars, and analyzed the characteristics of Waley's works and his understanding of Chinese culture, as well as the problems encountered during the retranslation process. He expounds the cultural perspective and method of Waley's research on witch culture, and praises the academic status of Welley's research.

A total of 10 sinologists tried the English translation of the chapter of "Chu $\mathrm{Ci}$ " before Hawkes: E. H. Parker, H. A. Giles, Joseph Edkins, J. Legge, Arthur Waley, Eduard Erkes, Franz Xaver Biallas, Lim Boon-keng, R. Payne and Yang Hsienyi and Gladys Yang (Wang liyun, Zhu Jun, \& Jiang Wuyou, 2013). But Hawkes has the most complete translation of "Chu Ci", whose English translation of Hawkes's "Chu $\mathrm{Ci}$ " is considered to be a classic translation with both academic and literary qualities. His translation works has made great contributions to the Chinese classics culture going abroad, and his translation viewpoints-accuracy and readabilityhave also been widely praised. Some scholars who have studied the literary or aesthetic qualities of several of these translations individually, highly praise Hawkes' literary accomplishment and aesthetic perspective in his translation about "Chu Ci" (Yang Cheng Hu, 2014; Peng Wanqing, 2018).

The English translation of Watson's "Chu Ci" made other contributions. It basically reproduced the image combination structure and syntactic structure of the original poems, mainly using literal translation methods. On the study of the characteristics of the original and translated poetry mythological image combinations, vanilla and accessories image combinations, and time image combinations, it is found that the literal translation method basically reproduces the aesthetic form and function of the original poem, but there are also cultural misreading and mistranslations of the original poem (Wei Jiahai, 2010).

As for translators in China, research is mainly focused on $\mathrm{Xu}$ 's translation. $\mathrm{Xu}$ Yuanchong's basic principle of expressing the truth through expression is well recognized, and his English translation of "Chu $\mathrm{Ci}^{\prime}$ embodies the characteristics of using the form to convey the spirit, or having both the form and the spirit (Yan Xiaojiang, 2015). Xu's translation of "Chu Ci" was a practice of "Three Beauty Theory", which reflected the spirit of truth-seeking in Western culture and the tradition of seeking beauty in Chinese culture. However, whether the "three beauty" can be realized at the same time and how to effectively spread the culture of Chu through translations is not sure (Yan Xiaojiang, 2012). To some extent, translation strategies determine the translator's translation style and direction. Study on translator's translation must be inseparable from studying translator's translation strategy. The translation strategy of localized cultural images is used in his translation process, that is, the assimilation strategy to avoid the 
loss and lack of cultural images. But, a single assimilation strategy sometimes fails to achieve the purpose of communication, and a translation strategy using "foreignization + assimilation" is better (Zhao Guoyue, 2013). "Chu Ci” by Yang Xianyi and Dai Naidi are with faithful and fluent translation styles which also tend to assimilation strategy, but there are improper translation in physical and geographical names and lack of commentary and so on (Liu Jin, 2013). Among Sun's translation with Xu's translation, Yang's and Dai's translations on the historical background, Sun's translation reflected the most detailed information on Chinese culture, and the English translation of classics was obvious (Liu Huali, 2012). However, it's not so convincing as it has much relevance to personal preference. But Sun's sense of responsibility and mission as a translator deserve our respect.

Although these translations are currently better translations, there are unavoidable flaws and omissions. If we always focus on these translations, the scope of the research will be significantly narrowed. Therefore, the scope of future research should be expanded as much as possible, and other unknown translations with their merits waited to be discovered. If we always focus our research on these translations, other translators may lose confidence in translation, which is very unfavorable for our culture to go global.

\section{Images}

Translation and cultural dissemination are inseparable. The complicated and various cultural images in "Chu Ci" have been an obstacle to English translations of Chinese classics, which has much to do with the dissemination of Chinese culture. The correct interpretation and effective translation of the traditional Chinese culture-loaded words by translators is an important guarantee for the completion of cross-cultural communication. In the translation of poetry, the success and failure of these imagery processes are directly related to the quality of poetry translation. Therefore, focus of research is still on the interpretation of various images in "Chu $\mathrm{Ci}^{\prime \prime}$.

The translation of "Chu $\mathrm{Ci}^{\prime}$ " should be based on the dissemination of traditional Chinese culture. Study on the translation of the cultural image and connotation of "Fusang" in "Li Sao" has been done (Zheng Jingjing, 2015). From Zhuo and Xu's translations, we can see that the choice of strategies and method choices during translation will have a significant impact on the transfer of cultural imagery and cultural connotation. The two English translations of $\mathrm{Xu}$ are designed to correctly interpret the original culture.

The main analysis process is that the translator first finds the images in the work, which include plant images, mythological images, and social images (Li Honglu, 2015). From the perspective of metaphor, the deep meaning of image hiding can be found. The words and phrases correspond to the original. This not only expresses the original thoughts and connotations, but also enables readers to generate the same psychological cognition and thinking concepts, which helps poetry to better communicate. Through research, it is found that there is a big difference between the two translators' treatment of the prototype image. Xu translators focus on domestication, while Zhuo translators focus on alienation. The translation effects obtained are also different (Li Honglu, 2015). 
However, because translation needs to face readers with different cultural backgrounds, and due to different background knowledge and thinking and cognitive methods, the problem of unsatisfactory words appears in the translation process. A comparative analysis of different English translations from the perspective of metaphor are made in cognitive linguistics, which gets out of the limitations of text analysis (Chen Fuming \& Zhan Hongwei, 2019).

Zhou Zhengdong and Zhang Zheng (2019) based on the self-made Chinese-English parallel corpus, compares the cultural images constructed by three sinologists, Arthur Waley, David Hawkes and Stephen Owen in their translations of Nine Songs from "Chu Ci" from three perspectives, including natural scenes, shamanistic practices and divine images. It also presents these images connotations, cultural functions and limitations in target language culture system, with a view to providing references for translating cultural images in traditional Chinese classics. Dong Fang (2019), on conceptual integration theory, uses Sun Dayu 's English version of "Chu $\mathrm{Ci}^{\prime \prime}$ as an example to explore the dynamic construction of metaphorical meaning of animals and plants in the English translation of "Chu Ci".

\section{Research Perspective}

As various theories emerging, scholars are not focusing on unilateral research, but from multiple aspects and new perspectives for study of "Chu $\mathrm{Ci}$ ". The existing research is mainly limited to the study of language imagery as we mentioned above, but part of the research has realized interdisciplinary research, which makes the current situation of the study of "Chu $\mathrm{Ci}^{\prime \prime}$ flourishing.

From the perspective of translation ethics, some scholars (Miao Jing \& Li Yingying, 2011) agree with Venuti's view on the translation and reproduction of the "characteristics of resistance to the main cultural values of the source language" in the original text. Xu's translation method is criticized for blindly naturalizing and reducing the heterogeneous components of Chinese poetry, which makes the translation lack Chinese flavor. The numerous animal images, plant images, and landscape images in "Chu $\mathrm{Ci}^{\prime}$ are difficult for people from different cultural background and they in some way represent the culture of China. In order to promotes the study

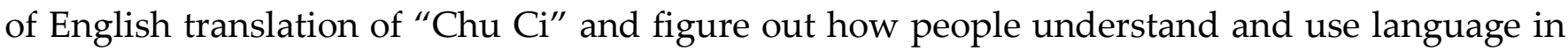
different cultural backgrounds, the study of relevant imagery are done from the perspective of Palmer's cultural linguistics (Chen Fuming \& Zhan Hongwei, 2019).

From the perspective of reception aesthetics which based on the reader's acceptance and response to understand the translator's aesthetic activities in literary translation, some translators (Yang Xianyi, 2001; Zhuo Zhenying, 2006; Sun Dayu, 2007; Xu Yuanchong, 2008) generally used the four methods of image transplantation, image deformation, image borrowing, and image omission (Yan Xiaojiang, 2013). The same year, she researched the translation of culturally loaded words in "Chu Ci" from the perspective of cultural translation. Taking Sun Dayu's Selected English Translations of Qu Yuan's Poems as an example, the author explores the translation of culturally-loaded words from five aspects as ecological, material, social, religious and language culture so as to study how to spread the Jingchu culture (Yan Xiaojiang, 2013). However, the focus of the author is still on translation skills, and no deep research has been done on how culture is spread. While other study of focus are on the English translation of Zhuo 
Zhenying's "Chu Ci" from the perspective of translation aesthetics, from the aspects of imagery, mood, rhythm, and language style.

Comparison has been done in order to figure out whether the translations of $\mathrm{Xu}$ Yuanchong, Zhuo Zhenying, Yang Xianyi, and Dai Naidie effectively conveyed the two cultural images of "thornthorn" and "Boyi" from the perspective of teleology (Zheng Jingjing, 2018). It shows, in the translation of culturally loaded words, the characteristics of Chinese culture should be reflected as much as possible, and the essence of Chinese culture should be spread. Other than the scholars mentioned above, there is comparative study between the translations at aboard and at home. Yu Yesheng and Jiang Lin (2018) take the English translations of "Chu Ci" by Hawkes, $\mathrm{Xu}$ Yuanchong, Yang Xianyi and Dynedale as examples. Their study was done by determining different domains, selecting different perspectives, highlighting different focal points and weighing the analysis of different degrees of detail from the perspective of cognitive translation, to study the translator's perception in image translation.

Evidence above shows the substantial improvement in the study of "Chu $\mathrm{Ci}^{\prime}$ from different perspectives, which is no longer single by combining culture and aesthetics and so on. However, there are only few research papers, which have not received much attention from scholars.

We can see that in the past two decades, the research perspectives and content of the English translation of "Chu $\mathrm{Ci}$ " have become more and more extensive. Undoubtedly, achievements have been made in some aspects. It is very clear that research for specific translations are mainly concentrated on the translations mentioned above, which are relatively widely accepted. Although some defects are there, they are still classic translations. The research perspective is diverse, but there is no focus point, and it doesn't go into a subject in depth. And the current research is mainly based on case studies, which is not systematic enough. In the future, comprehensive and systematic research must be strengthened.

\section{References}

[1] Arthur F. Wright, Arthur Waley. The Nine Songs: A Study of Shamanism in Ancient China[J]. Western Folklore, 1957: 69.

[2] Lefevere A. Translation/history/culture: A sourcebook[M]. Routledge, 2002.

[3] Michael T. Shamanic Eroticism in the Jiu Ge (nine Songs) of Early China[J]. Routledge, 2017: 1-20. doi: $10.1080 / 02549948.2017 .1309102$

[4] Michael T. Shamanism, Eroticism, and Death: the Ritual Structures of the Nine Songs in Comparative Context[J]. Religions, 2019: 17. doi: 10.3390/rel10010017

[5] Shadick H., Hawkes D. Ch'u Tz'u, the Songs of the South. an Ancient Chinese Anthology[J]. Circulation, 1959: 8-2005.

[6] Chen F, Zhan H. Image Metaphor in English translation of "Chu Ci"[J]. Sinogram Culture, 2019: 118-119.

[7] Chen F, Zhan H. A study on the English translation of natural images in "Chu Ci" from the perspective of cultural linguistics[J]. Sinogram Culture, 2019: 148-149. 
[8] Li H. On the Study of English Translation Strategy of Archetypal Images in "Chu Ci" - - A Case of $\mathrm{Xu}$ Yuanchong's and Zhuo Zhenying's Versions[J]. Journal of Xiangtan University (Philosophy and Social Sciences, 2015: 155-158.

[9] Li Y. An analysis of Hawkes' English translation of "Chu Ci" [J]. Foreign Languages and Their Teaching, 1992: 31-34, 50.

[10] Liu H. An analysis of Sun Dayu's English translation of "Chu Ci"[J]. Journal of Hebei Radio \& TV University, 2012: 40-42.

[11] Liu J. An analysis of Yan Xanyi's and Dai Naidie's English translation of "Chu Ci" - - Li Sao and Other Poems of Chu Yuan[J]. College English(Academic Edition), 2013: 231-234.

[12] Miu J, Li Y. English Translation of Chinese Classics from the Perspective of Translation Ethics - Exploration of Four Versions of "Chu $\mathrm{Ci}^{\prime}$ in China[J]. Journal of Hefei University of Technology (Social Sciences), 2011: 116-120.

[13] Peng W. Aesthetical Study on David Hawkes's Translation of "Chu Ci"[D]. Xiang Tan University, 2018.

[14] Shi S. Domestication and Foreignization: Reappearance of the Translated Cultural Images of “Chu Ci"[J]. Journal of Leshan Normal University, 2011: 88-90. doi: 10.3969/j.issn.10098666.2011.06.022

[15] Sun D. English Version of Selected Poems of Chu Yuan[M]. Shanghai: Shanghai Foreign Language Education Press, 2007.

[16] Wang L, Zhu J, Jiang Y. Hawkes' Translation Thoughts and the Formation of Classic Translations - - Taking the English Translation of "Chu Ci" as an Example[J]. Journal of Yanshan University (Philosophy and Social Science Edition), 2013: 31-38.

[17] Xu Y(trans.). Elegies of the South[M]. Beijing: CTPC, 2009.

[18] Yan X. On Imagery Translation of Elegies of the South from the Perspective of Reception Theory[J]. Journal of Southwest University of Science and Technology (Philosophy and Social Science Edition), 2013: 1164-1168.

[19] Yan X. Translation of Culturally-loaded Words in Elegies of the South from the Perspective of Cultural Translation - Taking Sun Dayu's English Version of Selected Poems of Chu Yuan as the Example[J]. Journal of Southwest University of Science and Technology (Philosophy and Social Science Edition), 2013: 65-69.

[20] Yan X. "Three Beauty Theory" in XU Yuanchong's English Version of Elegies of the South[J]. Journal of Nantong University (Social Sciences Edition), 2012: 92-96.

[21] Yang X, Yang G.(trans.). Selected Translations of "Chu Ci”[M]. Shanghai: Shanghai Guji Press, 1979.

[22] Yu Y, Jiang L. Exploring the Rendition of Imagery in Poetry of the South from the Perspective of Cognitive Translatology[J]. Minority Translators Journal, 2018: 76-83.

[23] Zhang X. On the Study of The Songs of Chu - Nine Songs by British Sinologist Willy[D]. East China Normal University, 2010: 76-83.

[24] Zhao G. An Analysis of the English Translation Strategies of Orientational Cultural Images in Chinese Classics - - Take the English Translation of Elegies of the South as an Example[J]. Journal of Beijing University of Chemical Technology (Social Sciences Edition), 2013: 70-75. 
[25] Zeng H. On the English Translation of The Verse of Chu in the Translation Aesthetics[J]. Journal of Yulin University, 2014: 108-110.

[26] Zeng J, Chen W. A Study of the English Translation of cultural Image of "Wenyu 文鱼” in "Chu Ci · Hebo" [J]. Popular Science, 2017: 135-136.

[27] ] Zeng J. A Study on Chinese-English Translation of the Culture Loaded Words in "Ju Song" from the Perspective of Skopos Theory[J]. University Education, 2018: 102-105.

[28] Zhou Z, Zhang Z. A Comparative Study of Cultural Images Based on Chinese-English Parallel Corpus in Nine Songs from Ch'u Tz'u Translated by Three Sinologists[J]. Language Education, 2019: 20-24, 45. 

or adapt the article content, providing a proper, prominent and unambiguous attribution to the authors in a manner that makes clear that the materials are being reused under permission of a Creative Commons License. Views, opinions and conclusions expressed in this research article are views, opinions and conclusions of the author(s). and European Journal of Literature, Language and Linguistics Studies shall not be responsible or answerable for any loss, damage or liability caused in relation to/arising out of conflicts of interest, copyright violations and inappropriate or inaccurate use of any kind content related or integrated into the research work. All the published works are meeting the Open Access Publishing requirements and can be freely accessed, shared, modified, distributed and used in educational, commercial and non-commercial purposes under a Creative Commons Attribution 4.0 International License (CC BY 4.0). 